\title{
Moisturizers versus Current and Next-Generation Barrier Repair Therapy for the Management of Atopic Dermatitis
}

\author{
Peter M. Elias Joan S. Wakefield Mao-Qiang Man \\ Department of Dermatology, UC San Francisco, and Dermatology Service, VA Medical Center, \\ San Francisco, CA, USA
}

\section{Keywords}

Antihistamines - Atopic dermatitis - Barrier function ·

Barrier response - Ceramides · Cytokines - Epidermal lipids ·

Kallikreins $\cdot$ Moisturizers $\cdot$ PPAR $\cdot \mathrm{pH}$

\begin{abstract}
We compare here the principal characteristics of over-thecounter moisturizers with physiologic lipid-based barrier repair therapy. Moisturizers are standard ancillary therapy for anti-inflammatory skin disorders, like atopic dermatitis (AD), and can attenuate the emergence of $A D$, the initial step in the "atopic march." But not all moisturizers are beneficial; some can make skin function worse, and can even induce inflammation, possibly accounting for the frequent occurrence of "sensitive skin" in women. In contrast, physiologic lipid-based barrier repair therapy, if comprised of the 3 key stratum corneum lipids, in sufficient quantities and at an appropriate molar ratio, can correct the barrier abnormality and reduce inflammation in $A D$, and perhaps in other inflammatory dermatoses.

(c) 2018 S. Karger AG, Basel
\end{abstract}

\section{Moisturizers Do Not Equate with Barrier Repair Therapy}

Types of Ingredients in Moisturizers and Their Mechanisms of Action

By definition, moisturizers contain occlusive ingredients, such as petrolatum or lanolin, which coat the surface of the skin with a water-repellent lipid layer that impedes the bidirectional movement of water across the skin. Because they block water loss out of the skin, these agents can temporarily ameliorate the xerosis that is characteristic of atopic dermatitis (AD) and age-associated eczematous disorders. Moreover, by improving the hydration of the stratum corneum (SC), they can dampen inflammation [1]. However, it is important to note that occlusive moisturizers do not address the underlying biochemical abnormalities of AD.

Many moisturizers also contain $\geq 1$ humectants, such as glycerin, which imbibe water from the surrounding atmosphere. AD typically flares during winter months when indoor humidity can decline drastically due to forced-air and radiant heating, so humectants are often paired with an occlusive agent such as petrolatum, to protect against further drying of the skin, which can otherwise exacerbate AD symptoms.

\section{KARGER}

(c) 2018 S. Karger AG, Basel

E-Mail karger@karger.com

www.karger.com/spp
Peter M. Elias, MD

Dermatology Service, VA Medical Center

4150 Clement Street, MS 190

San Francisco, CA 94121 (USA)

E-Mail peter.elias@ucsf.edu 
Many moisturizers also incorporate emollient vegetable oils such as olive, coconut, jojoba, or avocado. While these agents can impart an elegant texture to such formulations, they provide no scientifically proven benefits, with one key exception; certain vegetable oils, such as sunflower, safflower, borage, corn, and sea buckthorn are enriched in essential fatty acids and/or $\delta$-linoleic acid. These oils can: (i) improve barrier function [2, 3], (ii) reduce inflammation via the activation of peroxisome proliferator-activated receptors (PPARs) [4], and/ or (iii) even provide nutritional benefits [5]. Finally, botanical ingredients are increasingly being added to moisturizers, and some of these can be beneficial. For example, chamomile contains anti-inflammatory substances, such as apigenin, which can improve AD symptoms [6].

It should be noted that some popular over-the-counter moisturizers also include a skin-identical or synthetic ceramide, or pseudoceramide [7]. Although these ceramides, if provided at sufficient concentrations, can improve epidermal permeability barrier and SC hydration [8], their content in most formulations is usually too low to impart measurable benefits. Ceramides appear to be included in such preparations largely for marketing purposes. Moreover, as described below, if the ceramide is provided without the addition of the other 2 key physiologic lipids at an appropriate ratio, i.e., with cholesterol and $\geq 1$ fatty acids, barrier function deteriorates rather than improves. Studies have shown that all 3 constituents must be provided together in an equimolar ratio to restore barrier function after the disruption of normal skin [9].

\section{Moisturizers Can Harm Individuals with a Defective}

Barrier

In a "sensitive skin" animal model, we recently identified a serious flaw in most of the moisturizers currently on the market [10]. While they may appear harmless when applied to normal skin that displays a robust barrier, many of these products could prove to be toxic if/ when they are applied to the skin of individuals with selfreported sensitive skin, likely also involving subjects with a history of $\mathrm{AD}[10]$. However, these products rarely are tested in such "at-risk" individuals. Instead, typically, these subjects are specifically excluded from any such investigations. The bottom line is that, while short-term relief may be obtained with these agents, if they further disrupt the skin barrier they can initiate a vicious cycle that requires repeated applications of the same or alternate products.

\section{Barrier-Based Pathogenesis of AD}

\section{How Inherited Mutations in Structural Proteins Give}

Rise to $A D$

Though much attention in recent years has focused on filaggrin, $\mathrm{AD}$ is associated with mutations in a diverse group of structural and enzymatic proteins that interfere with either the loading and/or delivery of the lipid and enzymatic contents of lamellar bodies into the extracellular spaces of the SC [11]. Normally, these secreted lipids form stacks of lamellar bilayers that fill the extracellular spaces, accounting for around $10 \%$ of the mass of the SC in normal skin. In $\mathrm{AD}$, the failure to deliver a full complement of lipids to the SC results in reduced amounts of extracellular lipids, producing a "leaky" extracellular matrix that permits excessive loss of water [12]. An immediate consequence of a flawed delivery mechanism is a decline in the total lipid content needed to fill the extracellular spaces with lamellar bilayers. It also should be noted that, because the permeability and antimicrobial barriers are both closely linked and interdependent [13], a permeability barrier defect results in a parallel defect in antimicrobial defense that allows an unimpeded penetration of microbial pathogens and allergens into the skin (Fig. 1).

\section{The Link between Barrier Abnormality and the \\ Inflammatory Phenotype in $A D$}

Another consequence of the flawed barrier in $\mathrm{AD}$ further linking the barrier defect to the characteristic immunophenotype in $\mathrm{AD}$, is the so-called "cytokine cascade" [14]. In response to the sustained barrier defect, the epidermis produces a series of signaling molecules, including a host of cytokines and growth factors, in an inherently unsuccessful attempt to restore normal function [15]. Due to the underlying, inherited, biochemical abnormality in $\mathrm{AD}$, normal function cannot be restored. Hence, these signals continue to be generated, sustaining a signal cascade until a Th2- or Th17-dominant inflammatory milieu develops. Despite a host of recent articles espousing inflammation as the cause of dermatitis, it is this "outside-to-inside" paradigm of $\mathrm{AD}$ pathogenesis, due to the inherited barrier abnormality, that sustains a proinflammatory cytokine cascade [16] (Fig. 1).

\section{The Pathogenic Role of Elevated $\mathrm{pH}$ in $A D$}

An inevitable consequence of both the flawed barrier and the inflammation in $\mathrm{AD}$ is an elevation in $\mathrm{pH}$ on the skin surface [17].The deleterious consequences of an elevated $\mathrm{pH}$ in $\mathrm{AD}$ include the activation of yet another outside-to-inside cytokine cascade, that begins with the 
Fig. 1. The "outside-to-inside" homeostatic responses provoke a cytokine cascade that leads to inflammation in AD.

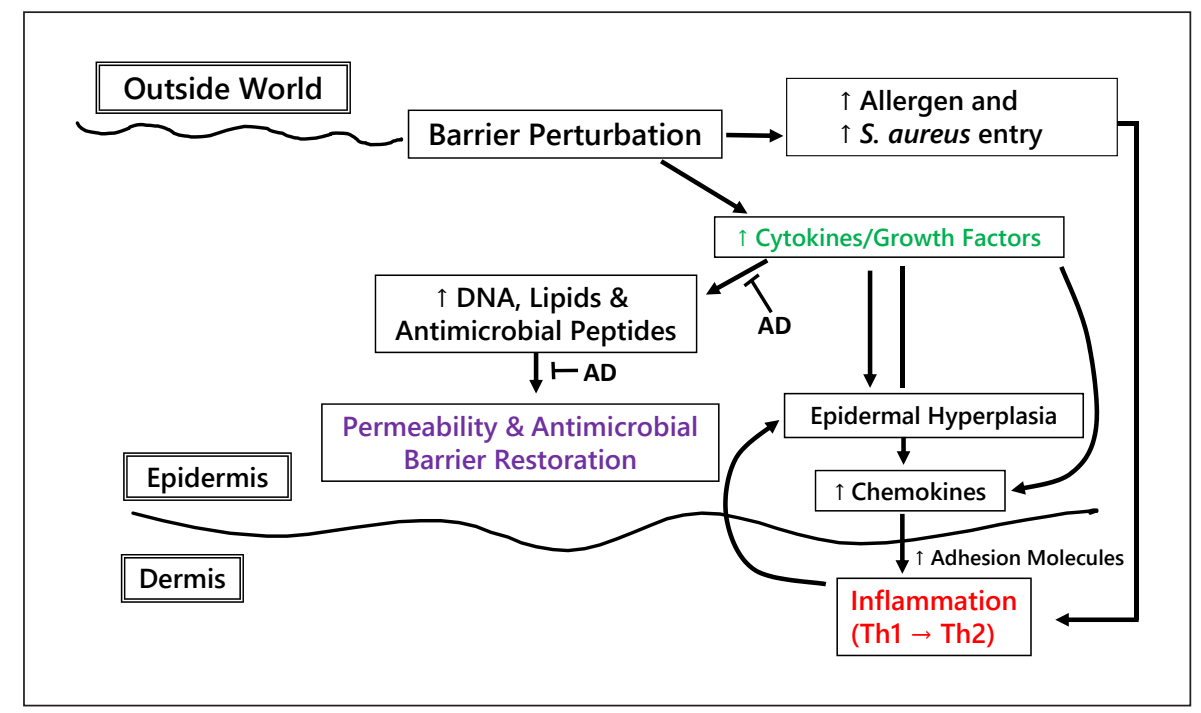

activation of the serine protease, kallikrein (KLK) 5, followed by the generation of the pro-Th2 cytokine, thymic stromal lymphopoietin (TSLP), which in turn recruits Th2 and Th17 cells that secrete the "bad" cytokines, i.e., interleukin (IL)-4, IL-5, IL-13, IL-17A, and IL-33 [18] (Fig. 2). Th2 cytokines further compromise the barrier by downregulating the synthesis of: (i) epidermal structural proteins [19], (ii) tight-junction proteins [20], (iii) ceramides [21], (iv) fatty acid elongases [22], and (v) a key antimicrobial peptide, LL-37 [23]. Hence, the initial outside-to-inside cytokine cascade in $\mathrm{AD}$ quickly morphs into an "outside-to-inside back to outside" vicious circle [24]. Furthermore, KLKs exhibit a neutral-to-alkaline $\mathrm{pH}$ optimum, and their activation in $\mathrm{AD}$ further compromises another set of critical functions (Fig. 2).

Finally, the low pH of normal SC (4.5-5) inhibits the growth of Staphylococcus aureus and Streptococcus pyogenes, so that the normal flora, e.g., Staphylococcus epidermidis and Corynebacterium thrive [17, 25]. In contrast, the elevated $\mathrm{pH}$ of the inflamed skin in $\mathrm{AD}$ favors pathogen colonization and growth.

\section{The Role of BRT in AD}

\section{Can Moisturizers Alone Improve AD?}

Current guidelines for the management of $\mathrm{AD}$ typically recommend the use of moisturizers along with antiinflammatory agents [26]. This approach seems prudent, since coapplication of moisturizers under nursing supervision have been shown to reduce reliance on topical ste-

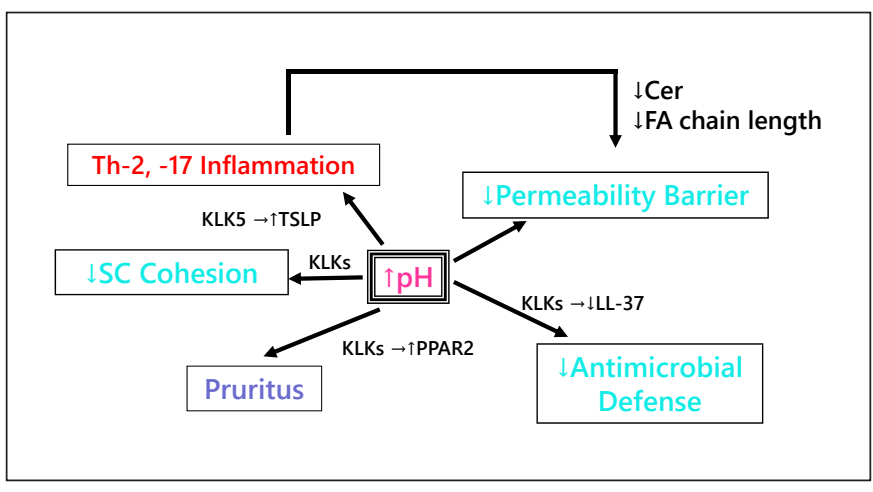

Fig. 2. Central role of an increased $\mathrm{pH}$ in $\mathrm{AD}$ pathogenesis (modified from [17]).

roids in $\mathrm{AD}$ management $[27,28]$. Recent studies, however, show that some commonly employed moisturizers can harm the skin if they are deployed in settings where the barrier is already compromised [28], as is certainly the case in $\mathrm{AD}$. Here, we will compare the key differences between ubiquitous, over-the-counter moisturizers and preparations formulated specifically to correct the biochemical abnormalities in AD. Although these mutations typically compromise structural proteins, their net effect is to compromise either the synthesis, loading, or secretion of lamellar body contents. The result of these aberrant mechanisms is both a global reduction in all 3 key barrier lipids, along with a further Th2-driven decline in ceramide content and fatty acid chain length (see above and [29]). By hydrating the SC, moisturizers can alleviate 
the xerosis that is such a prominent feature of $\mathrm{AD}$, but they have not yet been shown to provide stand-alone therapy for even mild cases of AD. Moreover, whether they even prevent the initial development of $\mathrm{AD}$, as suggested in several recent studies [30,31], is debatable, because another study has failed to show any preventive benefits of moisturizer therapy alone [32].

\section{Physiologic Lipid-Based Therapy of AD}

Topically applied physiologic lipids, in contrast to moisturizers, do not form an occlusive layer on the SC surface. Instead, they are quickly absorbed into the underlying nucleated cell layers, where they incorporate into nascent lamellar bodies as they form in the transGolgi apparatus of stratum spinosum and granulosum cells [9]. Once there, they join with de novo synthesized lipids, immediately prior to their secretion into the extracellular spaces. As shown in Figure 1, however, not only synthesis, but also secretion is impaired in $\mathrm{AD}$, resulting in a global reduction in the "big three" physiologic lipids (ceramides, including ceramide III or IV cholesterol, and free fatty acids such as palmitate). Therefore, in addressing first the reduced lipid content of the SC in $\mathrm{AD}$ (i.e., from approx. 10 to $5 \%$ of the weight of normal SC), these physiologic lipids ideally should be provided at a high, final concentration of at least $5 \%$. Then, because of the further Th2 cytokine-induced reduction in ceramide content of the SC, the 3 lipids ideally should be provided as a ceramide-dominant mixture (i.e., approx. a 3:1:1 molar ratio) [9], with a ceramide or synthetic pseudoceramide as the dominant species. In view of the significant $\mathrm{pH}$ abnormality in $\mathrm{AD}$, this final formulation should ideally be adjusted to a $\mathrm{pH}$ of $\leq 5$ in order to compensate for the elevated $\mathrm{pH}$ of the inflamed skin. As noted above, lowering the $\mathrm{pH}$ of the $\mathrm{SC}$ alone provides numerous potential benefits, including a reduction in inflammation, while also enhancing the permeability barrier, SC cohesion, and antimicrobial defense (Fig. 2). Fatty acids are not only critical for the barrier and as acidifying agents, some can even activate PPARa and $\operatorname{PPAR} \beta / \delta$, improving epidermal function and further reducing inflammation [4]. In addition, fatty acid activators of PPARs can: (i) prevent the emergence of steroid side effects [33], (ii) override the negative effects of calcineurin inhibitors on barrier function [34], and (iii) prevent rebound flares following the withdrawal of topical steroids [24]. Finally, several topical ingredients, including the triple lipids and even petrolatum, have been shown to enhance epidermal production of the key antimicrobial peptide, LL-37 [35].
Efficacy of Triple Physiologic Lipid-Based BRT in AD

Unlike moisturizers, topical ceramide-dominant, triple-lipid products amplify lipid production and delivery to the SC intercellular spaces, replenishing the lamellar bilayers that are critical for normal barrier function and antimicrobial defense. Chamlin et al. [36] evaluated 24 pediatric patients with recalcitrant $\mathrm{AD}$. While all of these patients continued to use standard therapy (including potent topical steroids and/or tacrolimus), the sole intervention was substituting each patient's previous moisturizer with a ceramide-dominant, triple-lipid product. Followup SCORAD (SCORing Atopic Dermatitis assessment) showed a rapid improvement in clinical scores in 22/24 patients. Not only did the clinical scores improve, both epidermal barrier function and SC cohesion were also enhanced. The ultrastructure of lipid-treated human epidermis has revealed enhanced lamellar membrane production, a change that was absent from patients previously treated with common moisturizers [36]. More recently, a ceramide-dominant, triple-lipid prescription formulation EpiCeram emulsion (online suppl. Table 1; see www.karger.com/doi/10.1159/000493641 for all online suppl. material) also improved skin barrier function in comparison to conventional moisturizers in $\mathrm{AD}$ patients [37]. This ceramide-dominant product was then assessed in a multicenter, investigator-blinded, comparative study of 121 pediatric patients, aged 6 months to 12 years, with moderate-to-severe AD [38]. Patients were randomized to either EpiCeram alone or a mid-potency, fluorinated steroid, fluticasone (Cutivate) cream. By 28 days, patients treated with EpiCeram alone demonstrated SCORAD scores that were comparable to fluticasone. Moreover, EpiCeram treatment not only reduced disease severity, but also pruritus, while improving sleep quality with an efficacy comparable to fluticasone. This study supports the potential utility of a physiologic lipid-based, barrier repair approach as monotherapy in the treatment of $\mathrm{AD}$.

\section{How BRT Is Anti-Inflammatory in AD}

Managing $\mathrm{AD}$ often requires the use of topical antiinflammatory agents (topical corticosteroids, topical calcineurin inhibitors or PDE4 inhibitors), and in adults with recalcitrant, moderate-to-severe $\mathrm{AD}$, systemic biologics (e.g., IL-4 or IL13 inhibitors). But in clinical settings, management should always focus on the skin barrier. Clinicians are presented with many choices for managing the compromised barrier that is a central participant in $\mathrm{AD}$ pathogenesis. Though parsing through these choices can be difficult, many moisturizers appear to pro- 
Table 1. Approaches to fixing the barrier in atopic dermatitis

\section{Long-standing approaches}

Educate (about soaps, hydration, $\downarrow$ stress)

Hydrate (emollients $\rightarrow \downarrow$ steroid usage)

$\downarrow S$. aureus carriage

Interrupt itch-scratch cycle ${ }^{\mathrm{a}}$

\section{More recent approaches}

Topical barrier repair (Cer-dominant [3:1:1] ratio of Cer, FFA, Chol)

Suberythemogenic UVB

Lower stratum corneum $\mathrm{pH}$

Serine protease inhibitors

$\mathrm{PAR}_{2}$ inhibitors

Enhance innate immunity ( $\uparrow$ AMP expression)

Stimulate filaggrin production, e.g., PPAR/LXR activators and naturally occurring bioflavonoids

$\downarrow$, decreased; $\rightarrow$, leads to; $\uparrow$, increased.

a Antihistamines benefit the barrier [48].

vide little or no benefit, and as noted above, some could even be harmful [10].

Animal studies suggest that moisturizers alone, by restoring SC hydration, reduce cytokine production, mast cell hypertrophy and degranulation, as well as epidermal hyperplasia $[1,39]$. To the extent that occlusive ingredients like petrolatum improve permeability barrier function, they too can dampen cytokine production. However, the anti-inflammatory activity of the triple physiologic lipid-based formulation can be attributed to several additional characteristics, which include: (i) inactivation of kallikreins that compromise SC structural integrity at a low $\mathrm{pH}$; (ii) inhibition of pathogen colonization with reductions in attendant, superantigen-initiated inflammation; and (iii) activation of two key lipid-processing enzymes, $\beta$-glucocerebrosidase and acidic sphingomyelinase, which generate ceramides required to form the extracellular lamellar bilayers [40]. Finally, (iv) as noted above, certain free fatty acids in these formulations can activate PPARs, which in turn can reduce inflammation by several parallel mechanisms [41].

\section{Next-Generation BRT for $A D$}

The recent emphasis on anti-inflammatory therapy, and particularly new biologics, has overshadowed efforts to bolster barrier function as primary or ancillary therapy for $\mathrm{AD}$. Yet, these potent agents are not appropriate for use in most children, and not for patients with relatively limited disease, particularly if they can be managed ef- fectively with currently available therapy, with wellknown side effect profiles. Among the available options to further enhance barrier function in $\mathrm{AD}$ are antihistamines, which though not particularly effective at controlling pruritus in $\mathrm{AD}$, have been shown to enhance barrier function [10] (Table 1). Lowering the $\mathrm{pH}$ alone is highly effective [42]; hence, any formulation developed for $\mathrm{AD}$ should be deployed at a reduced $\mathrm{pH}$. It would be logical to deploy KLK inhibitors, many of which are naturallyoccurring, such as a1-anti-trypsin inhibitor or soybean trypsin inhibitor. KLKs not only are directly destructive, but they also bind to and activate plasminogen activator type 2 receptor $\left(\mathrm{PAR}_{2}\right)$, which in turn blocks lamellar body secretion [43] and provokes pruritus [44]. Hence, small peptide inhibitors of PAR2 could yet enter the therapeutic armamentarium for $\mathrm{AD}$. Because reduced exposure to the benefits of suberythemogenic UV-B has been proposed as a key factor in the recent, urban resurgence of $\mathrm{AD}$ [45], it would seem prudent to recommend moderate amounts of exposure to ambient UV-B as a part of the management plan for AD patients. Finally, not only PPAR activators [46], but also several bioflavonoid ingredients, such as hesperidin and apigenin [47], have been shown to boost filaggrin production, and could therefore prove useful in those AD patients who do not exhibit double-allele mutation in Filaggrin gene expression.

\section{Acknowledgments}

Research reported in this publication was supported by the $\mathrm{Na}$ tional Institute of Arthritis, Musculoskeletal and Skin Diseases of the National Institutes of Health under Award No. AR061106, administered by the Northern California Institute for Research and Education, with additional resources provided by the Veterans Affairs Medical Center, San Francisco, CA, USA. This content is solely the responsibility of the authors and does not necessarily represent the official views of either the National Institutes of Health or the Department of Veterans Affairs.

\section{Disclosure Statement}

Dr. Elias is a coinventor of EpiCeram, licensed from the University of California to Primus Pharmaceuticals, LLC, Scottsdale, AZ, USA. 


\section{References}

1 Denda M, Sato J, Tsuchiya T, Elias PM, Feingold KR. Low humidity stimulates epidermal DNA synthesis and amplifies the hyperproliferative response to barrier disruption: implication for seasonal exacerbations of inflammatory dermatoses. J Invest Dermatol. 1998 Nov;111(5):873-8.

2 Hou DD, Di ZH, Qi RQ, Wang HX, Zheng S, Hong YX, et al. Sea Buckthorn (Hippophaë rhamnoides L.) Oil Improves Atopic Dermatitis-Like Skin Lesions via Inhibition of NF$\kappa \mathrm{B}$ and STAT1 Activation. Skin Pharmacol Physiol. 2017;30(5):268-76.

3 Darmstadt GL, Mao-Qiang M, Chi E, Saha SK, Ziboh VA, Black RE, et al. Impact of topical oils on the skin barrier: possible implications for neonatal health in developing countries. Acta Paediatr. 2002;91(5):546-54.

4 Schmuth M, Haqq CM, Cairns WJ, Holder JC, Dorsam S, Chang S, et al. Peroxisome proliferator-activated receptor (PPAR)-beta/delta stimulates differentiation and lipid accumulation in keratinocytes. J Invest Dermatol. 2004 Apr;122(4):971-83.

5 Darmstadt GL, Badrawi N, Law PA, Ahmed S, Bashir M, Iskander I, et al. Topically applied sunflower seed oil prevents invasive bacterial infections in preterm infants in Egypt: a randomized, controlled clinical trial. Pediatr Infect Dis J. 2004 Aug;23(8):719-25.

6 Man MQ, Hupe M, Man G, et al. Topical apigenin alleviates cutaneous inflammation in murine models. Evid Based Complement Alternat Med. 2012;2012:912028

7 Tessema EN, Gebre-Mariam T, Neubert RH, Wohlrab J. Potential Applications of PhytoDerived Ceramides in Improving Epidermal Barrier Function. Skin Pharmacol Physiol. 2017;30(3):115-38.

8 Danby SG, Brown K, Higgs-Bayliss T, Chittock J, Albenali L, Cork MJ. The Effect of an Emollient Containing Urea, Ceramide NP, and Lactate on Skin Barrier Structure and Function in Older People with Dry Skin. Skin Pharmacol Physiol. 2016;29(3):135-47.

9 Man MQ M, Feingold KR, Thornfeldt CR, Elias PM. Optimization of physiological lipid mixtures for barrier repair. J Invest Dermatol. 1996 May;106(5):1096-101.

10 Li Z, Hu L, Elias PM, Man MQ. Skin care products can aggravate epidermal function: studies in a murine model suggest a pathogenic role in sensitive skin. Contact Dermat. 2018 Feb;78(2):151-8.

11 Elias PM, Wakefield JS. Mechanisms of abnormal lamellar body secretion and the dysfunctional skin barrier in patients with atopic dermatitis. J Allergy Clin Immunol. 2014;134: 781-91.

12 Scharschmidt TC, Man MQ, Hatano Y, et al. Filaggrin deficiency confers a paracellular barrier abnormality that reduces inflammatory thresholds to irritants and haptens. J Allergy Clin Immunol. 2009;124:496-506.
13 Aberg KM, Man MQ, Gallo RL, Ganz T, Crumrine D, Brown BE, et al. Co-regulation and interdependence of the mammalian epidermal permeability and antimicrobial barriers. J Invest Dermatol. 2008 Apr;128(4):91725.

14 Brunner PM, Leung DY, Guttman-Yassky E. Immunologic, microbial, and epithelial interactions in atopic dermatitis. Ann Allergy Asthma Immunol. 2018 Jan;120(1):34-41.

15 Feingold KR, Schmuth M, Elias PM. The regulation of permeability barrier homeostasis. J Invest Dermatol. 2007 Jul;127(7):1574-6.

16 Elias PM, Hatano Y, Williams ML. Basis for the barrier abnormality in atopic dermatitis: outside-inside-outside pathogenic mechanisms. J Allergy Clin Immunol. 2008 Jun; 121(6): 1337-43.

17 Elias PM. The how, why and clinical importance of stratum corneum acidification. Exp Dermatol. 2017 Nov;26(11):999-1003.

18 Jang H, Matsuda A, Jung K, Karasawa K, Matsuda $\mathrm{K}$, Oida $\mathrm{K}$, et al. Skin $\mathrm{pH}$ Is the Master Switch of Kallikrein 5-Mediated Skin Barrier Destruction in a Murine Atopic Dermatitis Model. J Invest Dermatol. 2016 Jan;136(1): 127-35.

19 Howell MD, Novak N, Bieber T, Pastore S, Girolomoni $\mathrm{G}$, Boguniewicz $\mathrm{M}$, et al. Interleukin-10 downregulates anti-microbial peptide expression in atopic dermatitis. J Invest Dermatol. 2005 Oct;125(4):738-45.

20 Gruber R, Elias PM, Crumrine D, Lin TK, Brandner JM, Hachem JP, et al. Filaggrin genotype in ichthyosis vulgaris predicts abnormalities in epidermal structure and function. Am J Pathol. 2011 May;178(5):2252-63.

21 Hatano Y, Adachi Y, Elias PM, Crumrine D, Sakai T, Kurahashi R, et al. The Th2 cytokine, interleukin-4, abrogates the cohesion of normal stratum corneum in mice: implications for pathogenesis of atopic dermatitis. Exp Dermatol. 2013 Jan;22(1):30-5.

22 Berdyshev E, Goleva E, Bronova I, Dyjack N, Rios C, Jung J, et al. Lipid abnormalities in atopic skin are driven by type 2 cytokines. JCI Insight. $2018 \mathrm{Feb} ; 3(4): 3$.

23 Ong PY, Ohtake T, Brandt C, Strickland I, Boguniewicz M, Ganz T, et al. Endogenous antimicrobial peptides and skin infections in atopic dermatitis. N Engl J Med. 2002 Oct; 347(15):1151-60.

24 Hatano Y, Man MQ, Uchida Y, et al. Murine atopic dermatitis responds to peroxisome proliferator-activated receptors alpha and beta/delta (but not gamma) and liver $\mathrm{X}$ receptor activators. J Allergy Clin Immunol. 2010; 125:160-9.

25 Korting HC, Kober M, Mueller M, Braun-Falco $\mathrm{O}$. Influence of repeated washings with soap and synthetic detergents on $\mathrm{pH}$ and resident flora of the skin of forehead and forearm. Results of a cross-over trial in health probationers. Acta Derm Venereol. 1987;67(1):41-7.
26 Boguniewicz M, Fonacier L, Guttman-Yassky E, et al. Atopic dermatitis yardstick: practical recommendations for an evolving therapeutic landscape. Ann Allergy Asthma Immunol. 2018;120:10-22.

27 Cork MJ, Britton J, Butler L, Young S, Murphy R, Keohane SG. Comparison of parent knowledge, therapy utilization and severity of atopic eczema before and after explanation and demonstration of topical therapies by a specialist dermatology nurse. Br J Dermatol. 2003 Sep; 149(3):582-9.

28 Lowe AJ, Su JC, Allen KJ, Abramson MJ, Cranswick N, Robertson CF, et al. A randomized trial of a barrier lipid replacement strategy for the prevention of atopic dermatitis and allergic sensitization: the PEBBLES pilot study. Br J Dermatol. 2018 Jan;178(1):e19-21.

29 Janssens M, van Smeden J, Gooris GS, Bras W, Portale G, Caspers PJ, et al. Increase in shortchain ceramides correlates with an altered lipid organization and decreased barrier function in atopic eczema patients. J Lipid Res. 2012 Dec;53(12):2755-66.

30 Simpson EL, Chalmers JR, Hanifin JM, Thomas KS, Cork MJ, McLean WH, et al. Emollient enhancement of the skin barrier from birth offers effective atopic dermatitis prevention. J Allergy Clin Immunol. 2014 Oct;134(4):818-23.

31 Lowe AJ, Leung DY, Tang ML, Su JC, Allen $\mathrm{KJ}$. The skin as a target for prevention of the atopic march. Ann Allergy Asthma Immunol. 2018 Feb;120(2):145-51.

32 Horimukai K, Morita K, Narita M, Kondo M, Kabashima S, Inoue E, et al. Transepidermal water loss measurement during infancy can predict the subsequent development of atopic dermatitis regardless of filaggrin mutations. Allergol Int. 2016 Jan;65(1):103-8.

33 Demerjian M, Choi EH, Man MQ, Chang S, Elias PM, Feingold KR. Activators of PPARs and LXR decrease the adverse effects of exogenous glucocorticoids on the epidermis. Exp Dermatol. 2009 Jul;18(7):643-9.

34 Kim M, Jung M, Hong SP, Jeon H, Kim MJ, Cho MY, et al. Topical calcineurin inhibitors compromise stratum corneum integrity, epidermal permeability and antimicrobial barrier function. Exp Dermatol. 2010 Jun;19(6): 501-10.

35 Rodriguez-Martin M, Martin-Ezquerra G, Man MQ, Hupe M, Youm JK, Mackenzie DS, et al. Expression of epidermal CAMP changes in parallel with permeability barrier status. J Invest Dermatol. 2011 Nov; 131(11):2263-70.

36 Chamlin SL, Kao J, Frieden IJ, Sheu MY Fowler AJ, Fluhr JW, et al. Ceramide-dominant barrier repair lipids alleviate childhood atopic dermatitis: changes in barrier function provide a sensitive indicator of disease activity. J Am Acad Dermatol. 2002 Aug;47(2): 198-208. 
37 Kircik LH. Effect of skin barrier emulsion cream vs a conventional moisturizer on transepidermal water loss and corneometry in atopic dermatitis: a pilot study. J Drugs Dermatol. 2014 Dec;13(12):1482-4.

38 Sugarman JL, Parish LC. Efficacy of a lipidbased barrier repair formulation in moderateto-severe pediatric atopic dermatitis. J Drugs Dermatol. 2009 Dec;8(12):1106-11.

39 Denda M, Wood LC, Emami S, Calhoun C, Brown BE, Elias PM, et al. The epidermal hyperplasia associated with repeated barrier disruption by acetone treatment or tape stripping cannot be attributed to increased water loss. Arch Dermatol Res. 1996 May;288(5-6): 230-8.

40 Elias PM. The skin barrier as an innate immune element. Semin Immunopathol. 2007 Apr;29(1):3-14.
41 Mao-Qiang M, Fowler AJ, Schmuth M, Lau P, Chang S, Brown BE, et al. Peroxisome-proliferator-activated receptor (PPAR)-gamma activation stimulates keratinocyte differentiation. J Invest Dermatol. 2004 Aug; 123(2): $305-12$.

42 Hatano Y, Man MQ, Uchida Y, Crumrine D, Scharschmidt TC, Kim EG, et al. Maintenance of an acidic stratum corneum prevents emergence of murine atopic dermatitis. J Invest Dermatol. 2009 Jul;129(7):1824-35.

43 Demerjian M, Hachem JP, Tschachler E, Denecker G, Declercq W, Vandenabeele P, et al. Acute modulations in permeability barrier function regulate epidermal cornification: role of caspase-14 and the protease-activated receptor type 2. Am J Pathol. 2008 Jan;172(1): 86-97.

44 Elias PM, Steinhoff M. "Outside-to-inside" (and now back to "outside") pathogenic mechanisms in atopic dermatitis. J Invest Dermatol. 2008 May;128(5):1067-70.
45 Thyssen JP, Zirwas MJ, Elias PM. Potential role of reduced environmental UV exposure as a driver of the current epidemic of atopic dermatitis. J Allergy Clin Immunol. 2015 Nov;136(5):1163-9.

46 Schmuth M, Jiang YJ, Dubrac S, Elias PM, Feingold KR. Thematic review series: skin lipids. Peroxisome proliferator-activated receptors and liver $\mathrm{X}$ receptors in epidermal biology. J Lipid Res. 2008 Mar;49(3):499-509.

47 Hou M, Sun R, Hupe M, Kim PL, Park K, Crumrine $\mathrm{D}$, et al. Topical apigenin improves epidermal permeability barrier homoeostasis in normal murine skin by divergent mechanisms. Exp Dermatol. 2013 Mar;22(3):210-5.

48 Lin TK, Man MQ, Santiago JL, Park K, Roelandt T, Oda Y, et al. Topical antihistamines display potent anti-inflammatory activity linked in part to enhanced permeability barrier function. J Invest Dermatol. 2013 Feb; 133(2):469-78 